\title{
The Liquid Nitrogen Level Measurement for Cryogenic Fuel Tank
}

\author{
Tao Wang, Limin Wang, Zhicheng Wang and Yubei Liu \\ China Academy of Launch Vehicle Technology, Beijing Institute of Structure and Environment Engineering, Beijing, 10076 , \\ China
}

\begin{abstract}
Cryogenic fuel tanks are key parts of the launch vehicle. This paper presented a method of the liquid nitrogen level measurement for cryogenic fuel tank based on thermistors and metal film resistances. The measurement model and measurement principle had been detailed in this paper. Error analysis was preliminarily discussed. And the application condition of this method was introduced.
\end{abstract}

Keywords-cryogenic fuel tanks; liquid nitrogen level; thermistor; metal film resistance

\section{INTRODUCTION}

A finite-length circular cylindrical shell with its two ends capped with hemispherical shells or hemispheroidal shells of revolution is a popular geometry for pressure vessels [1]. These shapes of vessels also are used commonly as cryogenic fuel tanks for liquid-propellant launch vehicle [2]. And these Lightweight tanks to store cryogenic hydrogen are important components of spacecraft upper-stages, single stage to orbit vehicles, and solar thermal propulsion systems [3].

Low-temperature hydraulic test is employed to analyze the load conditions of cryogenic fuel tanks, and liquid nitrogen is used in the low-temperature hydraulic test. Strain and liquid nitrogen level are needed to be measured. The traditional methods of liquid nitrogen level measures have been limited due to the high cost of liquid nitrogen level sensors. Moreover, the measuring system for strain is non-compatible with liquid nitrogen level sensors, so additional measuring system is needed[4]. Occasionally, the method of measuring temperature of ektexine of the cryogenic fuel tanks has been employed. However, the measured results did not necessarily yield better accuracy[5]. They are more generally accepted as an indication to insure the conservatism of the designer.

In this paper, the proposed method based on thermistors and metal film resistances has served to alleviate these shortcomings and has been used in some type launch vehicle. As a special case, the presented method can also be used for measuring the liquid nitrogen level in the field of liquid oxygen vessels and liquid argon tanks.

\section{MODELING}

\section{A. The Cryogenic Fuel Tank Model}

The cryogenic fuel tank is shown in Figure 1.

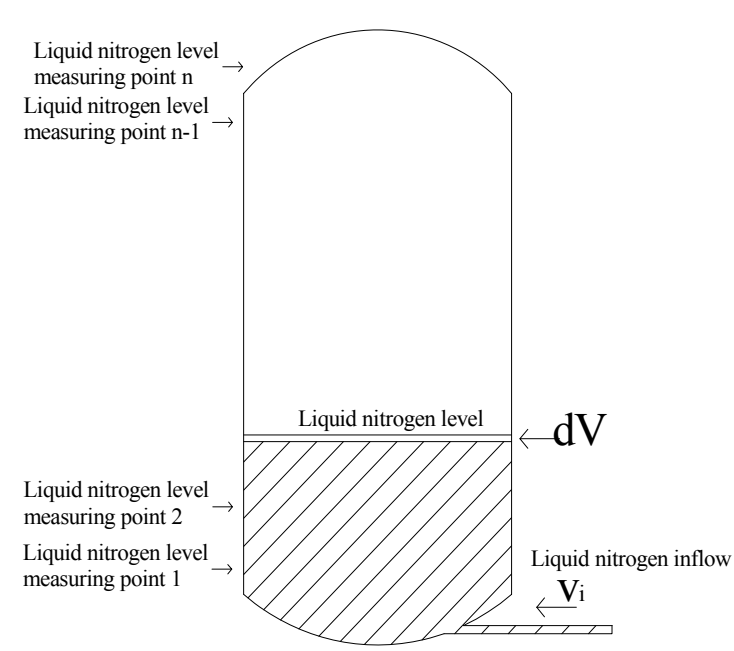

FIGURE I. THE CRYOGENIC FUEL TANK MODEL.

The relationship between liquid nitrogen level and inflow rate based on the mass conservation principle(vaporization of liquid nitrogen is neglected):

$$
\frac{d V}{d t}=v_{i}
$$

where: $\mathrm{V}=$ volume of liquid nitrogen

$$
\begin{aligned}
& \mathrm{v}_{\mathrm{i}}=\text { inflow rate } \\
& \mathrm{t}=\text { time. }
\end{aligned}
$$

\section{B. Measurement Model}

The Pt100 thermistors and $120 \Omega$ metal film resistances are installed on the inside of the cryogenic fuel tank, and without contacting the inner wall. When liquid nitrogen level gets to thermistors or metal film resistances, the metal film resistances would break, and the resistance value would more than $10 \mathrm{M} \Omega[6]$; the resistance value of the thermistor would change according to (2) from RTD tables[7].

$$
R(t)=R_{0} \times\left(1+A \cdot t+B \cdot t^{2}+C \cdot\left(t-100^{\circ} C\right) \cdot t^{3}\right)
$$

where: $\mathrm{R}_{0}=100 \Omega$

$$
\mathrm{A}=3.9083 \times 10^{-3 \circ} \mathrm{C}
$$




$$
\begin{aligned}
& \mathrm{B}=-5.775 \times 10^{-7 \circ} \mathrm{C} \\
& \mathrm{C}=-4.183 \times 10^{-13 \circ} \mathrm{C} \\
& \mathrm{t}=\text { temperature (the temperature of liquid nitrogen } \\
& \text { is }-196^{\circ} \mathrm{C} \text { ) }
\end{aligned}
$$

The cost of Pt100 thermistor is much higher than $120 \Omega$ metal film resistance, and the damage of metal film resistance is irreversible after exposed to liquid nitrogen. Therefore, only $120 \Omega$ metal film resistances are installed at the low liquid nitrogen level measuring points (the liquid nitrogen level would not fall)which have low cost; Both Pt100 thermistors and $120 \Omega$ metal film resistances are installed at the high liquid nitrogen levels measuring point (the liquid nitrogen level would fall and rise many times). The installation positions of Pt100 thermistors and $120 \Omega$ metal film resistances are shown in Figure 2.

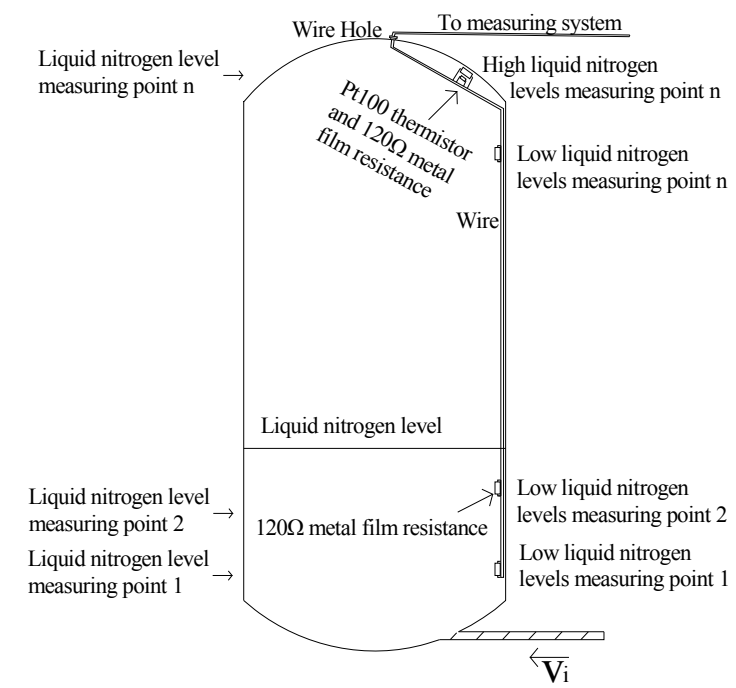

FIGURE II. INSTALLATION POSITIONS OF PT100 THERMISTORS AND $120 \Omega$ METAL FILM RESISTANCES.

\section{Measuring Principle}

The measuring principle of strain gage, resistance and thermistor is same as shown in Figure 3. Thus the measuring system of strain used in low-temperature hydraulic test could be employed to measure the resistances and thermistors.

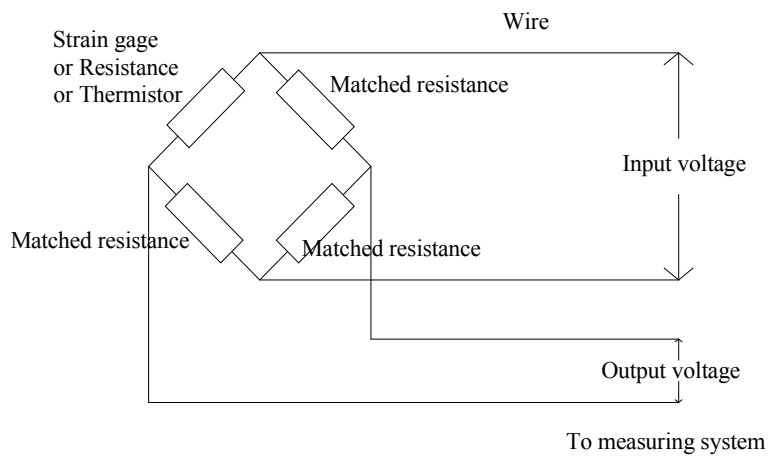

FIGURE III. ELECTRIC BRIDGE.
The most widely used principle to measure strain gage is the Wheatstone bridge. This bridge consists of four resistors. On the inputs voltage is called excitation voltage and measure the Output voltage. If the bridge is balanced, the output voltage will be zero.

One of the common configurations of the bridge is quarter bridge. In this case only one resistor is a thermistor or a metal film resistance and the other three are matched resistances with the same resistance value of thermistor or metal film resistance (that the bridge is balanced).

The basic equation of the bridge is

$$
\frac{\text { Vout }}{\text { Vin }}=\frac{d R / R}{4+2 \times d R / R}
$$

where: $\mathrm{V}_{\text {out }}=$ Output voltage

$\mathrm{V}_{\text {in }}=$ Input voltage

$\mathrm{R}=$ resistance value of matched resistance

$\mathrm{dR}=$ variable quantity of thermistor or a metal film resistance

The $2 * \mathrm{dR} / \mathrm{R}$ part is quite small ( $1 \%$ of elongation gives $1 \%$ error), thus simplify the (3) equation to:

$$
\frac{\text { Vout }}{\text { Vin }}=\frac{d R / R}{4}
$$

The resistance value of the thermistor from (2) is $20.68 \Omega$ with the liquid nitrogen temperature of $-196^{\circ} \mathrm{C}$. Thus the matched resistance from Figure 3 is $20.68+2 \mathrm{R}_{\mathrm{L}}(\Omega)$, and $\mathrm{R}_{\mathrm{L}}$ is resistance value of wire. When liquid nitrogen level gets to thermistor, the $\mathrm{V}_{\text {out }}$ from (4) would become zero and keep stable.

When liquid nitrogen level gets to metal film resistances, the metal film resistances would break, the $V_{\text {out }}$ from (4) would near input voltage and keep stable.

\section{ERRORS}

The time from liquid nitrogen level gets to thermistors or metal film resistances to the output voltage changed is called response time $t_{r}$. During the response time the liquid nitrogen level still rise. The $\mathrm{dV}$ from (1) is $\pi \mathrm{r}^{2} \mathrm{dh}$. The maximum response time of thermistor is $1 \mathrm{~s}[8]$, and the maximum response time of metal film resistances is $2 \mathrm{~s}$ [9]. Thus the errors is

$$
e=t_{r} \frac{\pi v_{i} r^{2}}{h}
$$

where: $r=$ internal diameter of circular cylindrical shell

$\mathrm{h}=$ high of cryogenic fuel tank 
$\mathrm{v}_{\mathrm{i}}=$ inflow rate

$\mathrm{t}_{\mathrm{r}}=$ response time, $\mathrm{t}_{\mathrm{r}}=1$ at high liquid nitrogen level measuring point and $t_{r}=2$ at low liquid nitrogen level measuring point

\section{APPLICATION}

Liquid nitrogen level sensors, thermistors and metal film resistances were employed in a certain test. Experiments show that performance of the present method is evident with respect to the liquid nitrogen level sensors. The installation positions of Pt100 thermistors and $120 \Omega$ metal film resistances in this test are shown in Figure 4. The test results is shown in Figure 5.

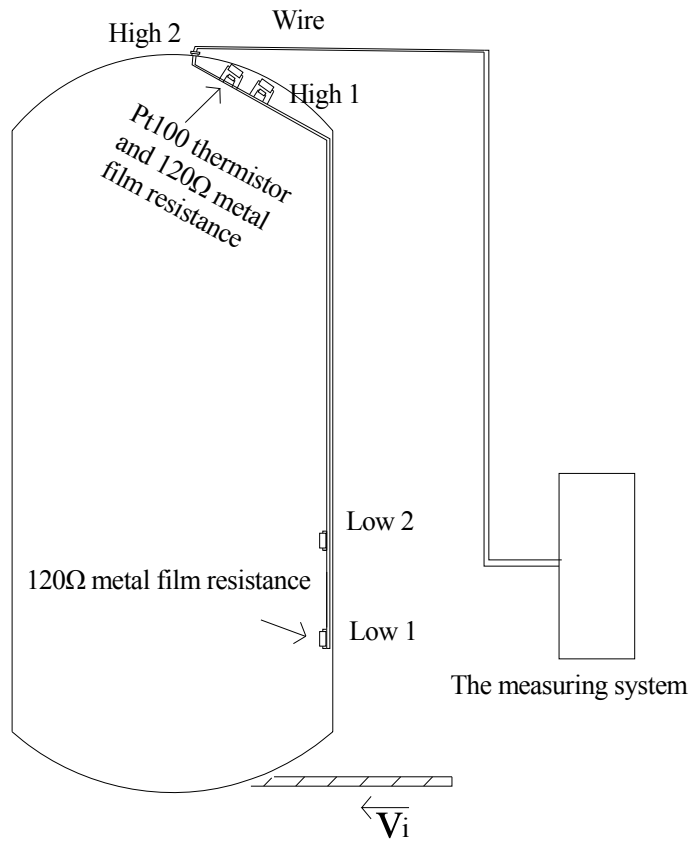

FIGURE IV. THE INSTALLATION POSITIONS OF Pt100 THERMISTORS AND $120 \Omega$ METAL FILM RESISTANCES IN TEST.

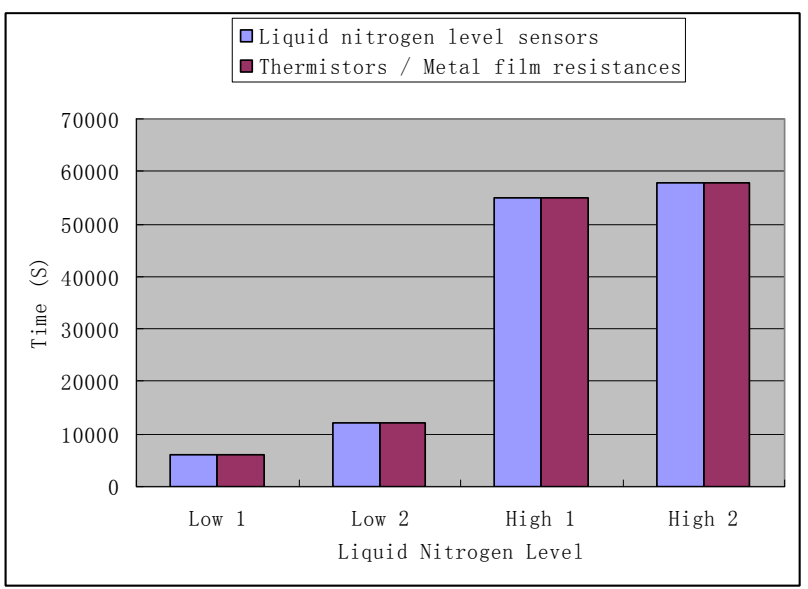

FIGURE V. THE TEST RESULTS.
The high and internal diameter of cryogenic fuel tank are $27 \mathrm{~m}$ and $3 \mathrm{~m}[10]$, and the inflow rate in the test is $0.017 \mathrm{~m}^{3} / \mathrm{s}$. The error of high liquid nitrogen level measuring point from (5) is $2 \%$, and the error of low liquid nitrogen level measuring point from (5) is $4 \%$.

\section{CONCLUSIONS}

In this paper, a method of the liquid nitrogen level measurement for cryogenic fuel tank based on thermistors and metal film resistances was proposed. The method has many advantages such as low cost, direct measurement, easy to accomplish and measuring accuracy in comparison with traditional methods. Error analysis was preliminarily discussed and the method had been applied in a low-temperature hydraulic test.

\section{REFERENCES}

[1] Timoshenko, S. P. and S.W. Krieger, Theory of Plates and Shells, McGraw-Hill Book Co., Inc., New York, 1959, pp.481-485

[2] Stephens, Craig A. and Gregory J. Hanna, Thermal Modeling and Analysis of a Cryogenic Tank Design Exposed to Extreme Heating Profiles, NASA CR-186012, 1991.

[3] Laug K, The Solar Propulsion Concept is Alive and well at the Astronautics Laboratory, (AFSC), Edwards Air Force Base, CA, JANNAF Propulsion Meeting, Cleveland OH, May 1989.

[4] G. Leeman, H. Jenny, H. R. Hidber, Design of a liquid nitrogen level detector using high-Tc superconductors, Physica C Superconductivity. Jun. 1988, pp.1427-1428.

[5] K. Srinivasan, J. Altin, Ripple-free liquid-nitrogen level controller for long-term operation, Review of Scientific Instruments, 1983, pp.795.

[6] C. C. Winding, L. Topper, B. V. Baus, Metal-Film Resistance Thermometers for Measuring Surface Temperatures, Industrial \& Engineering Chemistry, 1955, 47 (3), pp.386-392.

[7] K. Mosbach, B. Danielsson, Thermal bioanalyzers in flow streams, Analytical Chemistry, 1981, 53 (1), pp.83A-94A.

[8] C.J. Martin, A.N.R. Law, Design of thermistor probes for measurement of ultrasound intensity distributions, Ultrasonics, Mar.1983, pp.85-90.

[9] T. Clarysse, I. Hoflijk, Metal film characterization with qualified spreading resistance, Journal of Vacuum Science \& Technology, 2004, pp.444.

[10] L. S. He: Launch Vehicles Design, Beihang University Press, 2004, pp. 246 